\title{
Single-pulse stimulation of cerebellar nuclei stops epileptic thalamic activity
}

\author{
Oscar H.J. Eelkman Rooda a, b, 1 , Lieke $\operatorname{Kros}^{\mathrm{a}}{ }^{1}$, Sade J. Faneyte ${ }^{\mathrm{a}}$, Peter J. Holland ${ }^{\mathrm{c}}$, \\ Simona V. Gornati a, Huub J. Poelman a, Nico A. Jansen ${ }^{\text {d, e }}$, Else A. Tolner ${ }^{\text {d, e }}$, \\ Arn M.J.M. van den Maagdenberg ${ }^{\text {d, e }}$, Chris I. De Zeeuw ${ }^{\text {a, f }}$, Freek E. Hoebeek ${ }^{\mathrm{a}, \mathrm{g},{ }^{*}}$ \\ a Department of Neuroscience, Erasmus Medical Center, 3015, AA Rotterdam, the Netherlands \\ ${ }^{\mathrm{b}}$ Department of Neurosurgery, Erasmus Medical Center, 3015, AA Rotterdam, the Netherlands \\ ' School of Psychology, University of Birmingham, Birmingham, United Kingdom \\ d Department of Neurology, Leiden University Medical Center, 2300, RC Leiden, the Netherlands \\ e Department of Human Genetics, Leiden University Medical Center, 2300, RC Leiden, the Netherlands \\ ${ }^{\mathrm{f}}$ Netherlands Institute for Neuroscience, Royal Dutch Academy for Arts and Sciences, 1105, BA Amsterdam, the Netherlands \\ ${ }^{g}$ Department for Developmental Origins of Disease, University Medical Center Utrecht Brain Center and Wilhelmina Children's Hospital, Utrecht Medical \\ Center, 3508, AB Utrecht, the Netherlands
}

\section{A R T I C L E I N F O}

\section{Article history:}

Received 20 April 2020

Received in revised form

5 April 2021

Accepted 3 May 2021

Available online 20 May 2021

\section{Keywords:}

Cerebellum

Generalized absence seizures

Optogenetic neurostimulation

Thalamus

\begin{abstract}
A B S T R A C T
Background: Epileptic (absence) seizures in the cerebral cortex can be stopped by pharmacological and optogenetic stimulation of the cerebellar nuclei $(\mathrm{CN})$ neurons that innervate the thalamus. However, it is unclear how such stimulation can modify underlying thalamo-cortical oscillations.

Hypothesis: Here we tested whether rhythmic synchronized thalamo-cortical activity during absence seizures can be desynchronized by single-pulse optogenetic stimulation of $\mathrm{CN}$ neurons to stop seizure activity.

Methods: We performed simultaneous thalamic single-cell and electrocorticographical recordings in awake tottering mice, a genetic model of absence epilepsy, to investigate the rhythmicity and synchronicity. Furthermore, we tested interictally the impact of single-pulse optogenetic CN stimulation on thalamic and cortical recordings.

Results: We show that thalamic firing is highly rhythmic and synchronized with cortical spike-and-wave discharges during absence seizures and that this phase-locked activity can be desynchronized upon single-pulse optogenetic stimulation of $\mathrm{CN}$ neurons. Notably, this stimulation of $\mathrm{CN}$ neurons was more effective in stopping seizures than direct, focal stimulation of groups of afferents innervating the thalamus. During interictal periods, $\mathrm{CN}$ stimulation evoked reliable but heterogeneous responses in thalamic cells in that they could show an increase or decrease in firing rate at various latencies, bi-phasic responses with an initial excitatory and subsequent inhibitory response, or no response at all. Conclusion: Our data indicate that stimulation of $\mathrm{CN}$ neurons and their fibers in thalamus evokes differential effects in its downstream pathways and desynchronizes phase-locked thalamic neuronal firing during seizures, revealing a neurobiological mechanism that may explain how cerebellar stimulation can stop seizures.
\end{abstract}

๑ 2021 The Author(s). Published by Elsevier Inc. This is an open access article under the CC BY-NC-ND license (http://creativecommons.org/licenses/by-nc-nd/4.0/).

\footnotetext{
* Corresponding author. Department of Neuroscience, Erasmus Medical Center, 3015, AA Rotterdam, the Netherlands.

E-mail address: f.e.hoebeek@umcutrecht.nl (F.E. Hoebeek).

1 These authors contributed equally.
}

\section{Introduction}

Generalized epilepsy is a highly prevalent and debilitating seizure disorder involving large-scale thalamo-cortical networks [1]. Focal activity in a part of the cerebral cortex becomes hypersynchronous and rapidly spreads to large-scale networks leading to generalized seizures [2-6]. Even though many patients suffering from generalized epilepsy respond well to pharmacological 
therapy, the disorder remains refractory to drug treatment in an estimated $20-40 \%$ of patients [7,8]. For these patients neurostimulation may be an effective alternative $[9,10]$.

Thalamic neurostimulation has been shown effective in reducing seizure occurrence in some patients with refractory epilepsy $[11,12]$. Stimulation of brain regions that directly project to the dorsal thalamus has been shown to ameliorate epileptic seizures in experimental settings [10,13-15]. We recently showed that optogenetic stimulation of cerebellar nuclei $(\mathrm{CN})$ neurons reliably stops generalized absence seizures in mouse models [15]. At present it is unclear why this approach is so effective. Possibly, $\mathrm{CN}$ stimulation is efficient in stopping thalamo-cortical oscillations, because of their diverse, direct and indirect sets of innervation routes of the thalamus, exerting different effects that together can alter synchronous activity in a powerful fashion. Indeed, $\mathrm{CN}$ do not only directly innervate the thalamus, but they presumably also provide indirect afferent inputs via regions like the zona incerta and superior colliculus [16-18]. Here we tested whether stimulation of $\mathrm{CN}$ neurons, which project to the thalamus directly and indirectly via multiple routes, is more effective in stopping these presumptively synchronized oscillations than focal stimulation of different groups of isolated $\mathrm{CN}$ axons within the thalamus. We set out to study this in tottering mice, which exhibit behavioral absence seizures accompanied by electrocorticographic (ECoG) generalized spike-and-wave discharges (GSWDs) due to a P601L missense mutation in the $\alpha_{1 \mathrm{~A}}$ subunit of voltage-gated Cav2.1 Ca ${ }^{2+}$ channels [19].

Our findings indicate that single-pulse optogenetic CN stimulation evokes a wide range of heterogeneous responses in thalamic relay neurons (TRN) at various latencies during interictal states and that the same stimulation can desynchronize thalamic activity during seizures, matching the highly efficient anti-seizure effect, measured in the ECoG. The high success rate of seizure disruption upon $\mathrm{CN}$ stimulation is not achieved by selectively stimulating subpopulations of cerebello-thalamic afferents in various thalamic nuclei.

\section{Material and Methods}

\section{Experimental model and subject details}

Data were collected from 4- to 30-week-old male and female homozygous tottering mice and their wild type littermates, which were kept on a C57BL/6NHsd genetic background. PCR using 5'TTCTGGGTACCAGATACAGG-3' (forward) and 5'-AAGTGTCGAAGTTGGTGCGC-3' (reverse) primers (Eurogentech, Seraing, Belgium) and restriction enzyme $N s b$ I identified the tottering mutation in postnatal day 9-12 tissue. All surgical and experimental procedures were performed in accordance with the European Communities Council Directive. Protocols were reviewed and approved by the institutional experimental animal committees (DEC).

\section{Method details}

\section{Viral infection}

Stereotactic viral injections were performed as previously described [15]. We bilaterally injected virus-containing solutions (100-120 $\mathrm{nL}$ at $\sim 20 \mathrm{~nL} / \mathrm{min}$ ) to transfect neurons in the interposed and lateral $\mathrm{CN}$ with Channelrhodopsin-2 (AAV2-hSynChr2(H134R)-EYFP) or AAV2-hSyn-EYFP in mice anesthetized with $1.5 \%$ isoflurane. After $10 \mathrm{~min}$ the injection pipette was slowly retracted and optic fibers ( $200 \mu \mathrm{m}$ diameter; CFML22L05, Thorlabs, Newton, NJ, USA) were implanted $\sim 200 \mu \mathrm{m}$ above the injection site
[20]. Stereotactic coordinates for $\mathrm{CN}$ injections were $2.5 \mathrm{~mm}$ posterior to lambda, $2.2 \mathrm{~mm}$ lateral to the midline and $2.2 \mathrm{~mm}$ below the pial surface. Viral vectors were originally designed by Dr. K. Deisseroth and were acquired from the University of North Carolina vector core [21]. Mice injected with viral vectors were used for both freely behaving and head-fixed experiments.

\section{Preparation and execution of recordings in freely behaving mice}

All surgical procedures were performed under isoflurane anesthesia (induction 4\%; maintenance $1.5 \%$ in oxygen-enriched air). Body temperature during surgery was maintained at $37{ }^{\circ} \mathrm{C}$ by a heating pad (FHC, Bowdoin, ME, USA). Electrodes were placed at the following coordinates ( $\mathrm{mm}$ to bregma): $-1.0 \mathrm{AP} ;+3.5 \mathrm{ML} ;-0.6$ DV (right S1; single $75 \mu \mathrm{m}$ platinum (Pt)/iridium (Ir) electrodes, PT6718; Advent Research Materials, Oxford, UK); or 1.0 AP; $-1.5 \mathrm{ML}$; $-0.6 \mathrm{DV}$ (right M1; single Pt/Ir electrodes) for LFP recordings; $-1.3 \mathrm{AP}$; +1.25 $\mathrm{ML}$; $-3.1 \mathrm{DV}$ (right VL; paired Pt/Ir); or $-1.8 \mathrm{AP} ;+0.75 \mathrm{ML} ;-3.0 \mathrm{DV}$ (right $\mathrm{CL}$; paired $\mathrm{Pt} / \mathrm{Ir}$ ); or -1.8 $\mathrm{AP}$; +1.6 ML; $-3.0 \mathrm{DV}$ (right VPL/VPM; paired Pt/Ir) for MUA recordings; two ball-tip electrodes $(\mathrm{Ag} / \mathrm{Ag}, 75 \mu \mathrm{m})$ were positioned just posterior from lambda above the cerebellum to serve as reference and ground electrodes. Electrodes were connected to a 7channel pedestal (E363/0 socket contacts and MS373 pedestal; Plastics One, Roanoke, VA, USA) and secured to the skull using lightactivated bonding primer and dental cement (Kerr optibond/ premise flowable, DiaDent Europe, Almere, Netherlands). Carprofen $(5 \mathrm{mg} / \mathrm{kg}$, s.c.) and Temgesic ( $0.1 \mathrm{mg} / \mathrm{kg}$, s.c.) were administered for post-operative pain relief. After a recovery period (range 2.5-11 days; median 6.7 days), electrophysiological recordings were performed in freely behaving animals. Recording sessions typically took place between 9:00 and 17:00, i.e. during the light period (for further details see Ref. [22]). We visually inspected the behavior of the mice for short periods of time (i.e., usually for 15-30 min).

\section{Preparation for head-fixed recording}

ECoG electrode implantation in M1 and S1 cortices was performed as previously described [15]. To enable extracellular recordings from thalamic neurons, a subset of mice received bilateral parietal bone craniotomies ( $1.5 \mathrm{~mm}$ diameter). In another subset of mice, the thalamic complex was implanted with optic fibers. These fibers were positioned using the following coordinates (in degrees $\left({ }^{\circ}\right)$ relative to the interaural axis and in $\mathrm{mm}$ relative to bregma): $\mathrm{VL}: 22^{\circ}$ roll angle, $-1.2 \mathrm{AP},-3.0 \mathrm{ML},-3.1 \mathrm{DV}$; $\mathrm{VM}$ : $2^{\circ}$ roll angle, $-1.2 \mathrm{AP},-1.1 \mathrm{ML},-3.3 \mathrm{DV} ; \mathrm{CL} / \mathrm{CM}$ : $0^{\circ}$ roll angle, -1.3 $\mathrm{AP},-0.75 \mathrm{ML},-3.0 \mathrm{DV}$; zona incerta: $0^{\circ}$ roll angle, -2.5 AP, $-1.75 \mathrm{ML},-3.6 \mathrm{DV})$. The exposed tissue was surrounded by a recording chamber, covered with tetracycline-containing ointment (Terra-cortril; Pfizer, New York, NY, USA) and silicon wax (Twinsil speed; Picodent, Wipperfürth, Germany). Mice were allowed to recover for more than 5 days before experiments were performed.

\section{In vivo extracellular electrophysiology}

Following a 2-hr daily accommodation session in the setup on the first two days we performed recordings in awake, head-fixed mice on the third day lasting no longer than 4 hrs. Although being head-fixed, the mice were able to move all limbs freely. We visually inspected the mice for repetitive movements during synchronous cortical activity (GSWDs), but we found no correlation [15]. For extracellular single-unit recordings, custom-made, borosilicate glass capillaries (OD $1.5 \mathrm{~mm}$, ID $0.86 \mathrm{~mm}$; resistance 8-12 M $\Omega$; taper length $\sim 5 \mu \mathrm{m}$; tip diameter $0.5 \mu \mathrm{m}$ ) (Harvard Apparatus, Holliston, MA, USA) filled with $2 \mathrm{M} \mathrm{NaCl}$ were 
A
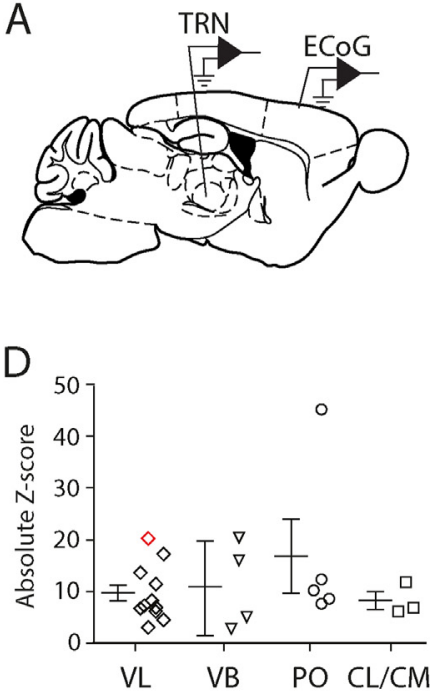
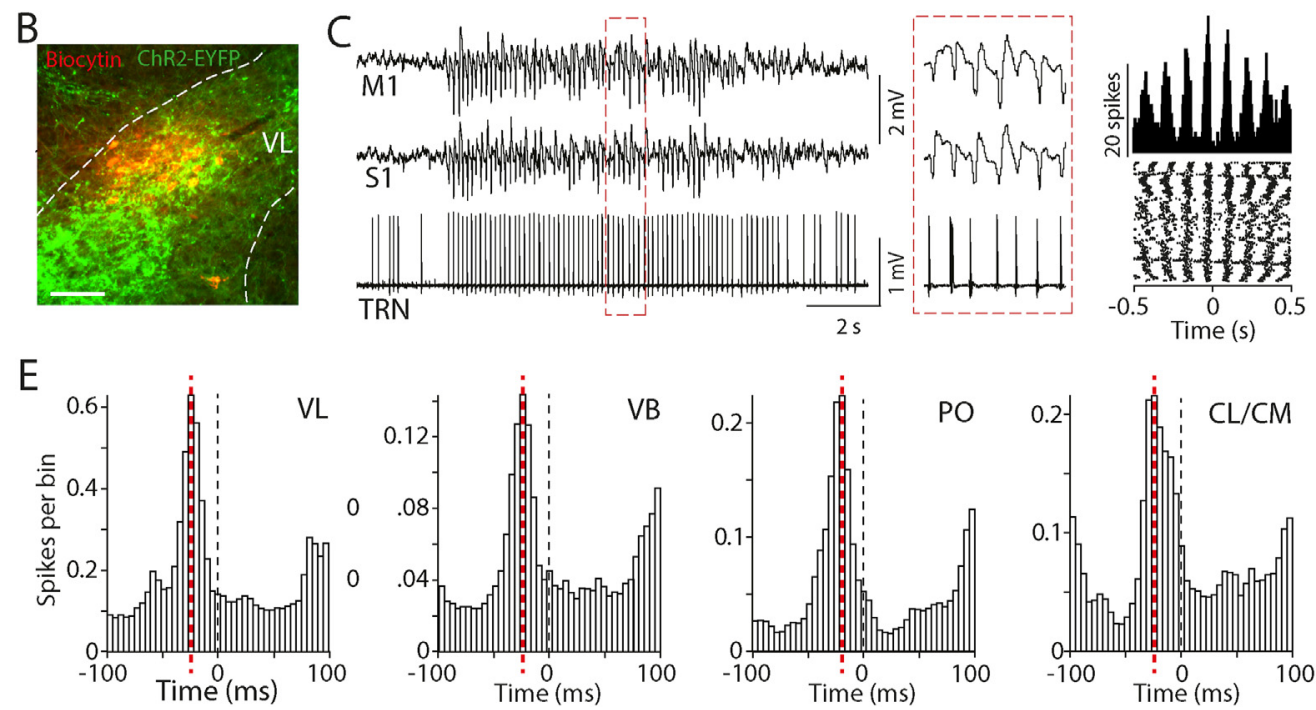

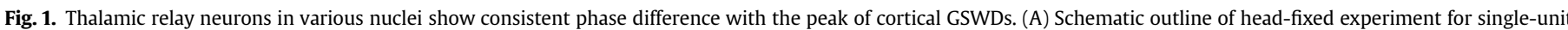

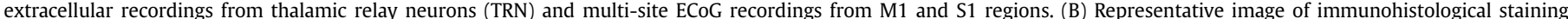

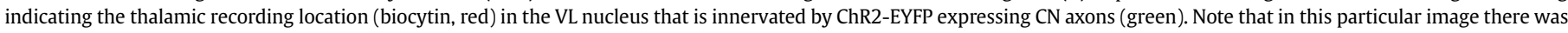

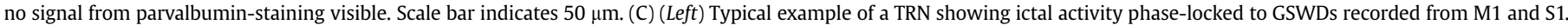

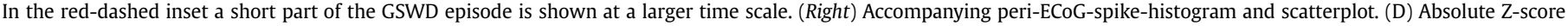

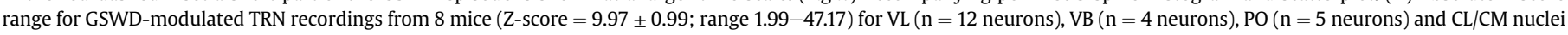

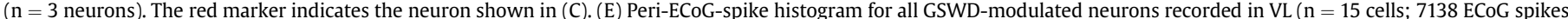

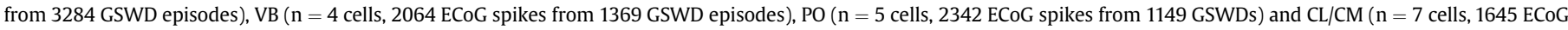

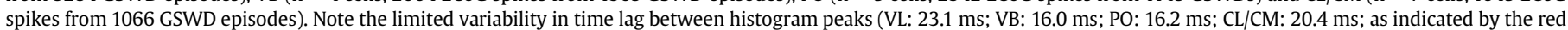

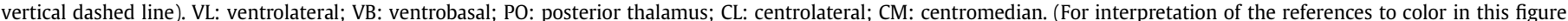
legend, the reader is referred to the Web version of this article.)

positioned stereotactically using an electronically driven pipette holder (SM7; Luigs \& Neumann, Ratingen, Germany). Stereotactic coordinates for thalamic recordings were tailored to the different thalamic nuclei and a subset of recording sites was identified using iontophoretic injections of biocytin (1.5\%, 1-min, 4-s on/off, 50\% duty cycle, $4 \mu \mathrm{A}$ ), which was present in the $\mathrm{NaCl}$-filled recording pipette. Thalamic neurons were considered as located in the same nucleus when recorded $\leq 100 \mu \mathrm{m}$ from a marked recording site. See Suppl. Material and Methods for additional (interictal optogenetic) ECoG recording settings.

\section{Optogenetic stimulation}

For extracellular recordings combined with optogenetic $\mathrm{CN}$ or thalamic stimulation brief pulses $(50 \mathrm{~ms})$ of blue $(470 \mathrm{~nm})$ light were used to activate ChR2-infected $\mathrm{CN}$ neurons. Optic fibers (for CN stimulation: inner diameter $200 \mu \mathrm{m}$, numerical aperture (NA) 0.39; for thalamic stimulation: inner diameter $105 \mu \mathrm{m}$, NA 0.22 ; Thor Labs Newton, NJ, USA) were placed $\sim 200 \mu \mathrm{m}$ from the injection site and connected to $470 \mathrm{~nm}$ LED sources (Thor Labs). Light intensity at the tip of the implantable fiber was $550 \pm 50 \mu \mathrm{W} / \mathrm{mm}^{2}$. We chose these optic fiber diameters guided by the estimated light intensity in the brain [23] so as to ensure that in $\mathrm{CN}$ sufficient neurons would be activated and that in thalamus a sufficient number of $\mathrm{CN}$ axons were activated. LEDs were activated for $50 \mathrm{~ms}$ at $0.2 \mathrm{~Hz}$ or by a closed-loop GSWD-detection system [15,24]. In both head-fixed and freely behaving experiments we ensured that the optical stimulation did not induce gross motor movements.

\section{Pharmacological modulation of CN neurons}

The procedure to increase $\mathrm{CN}$ action potential firing was performed as described previously [15,24]. Briefly, we located CN neurons after which we recorded $1 \mathrm{hr}$ of 'baseline' ECoG. After this, an injection was made with $100 \mu \mathrm{M}$ gabazine $\left(\mathrm{GABA}_{\mathrm{A}}\right.$-antagonist SR-95531; Tocris) dissolved in saline combined with a fluorescent dye (Evans Blue; $1 \%$ in saline) for histological verification. Next, we recorded thalamic activity for $30 \mathrm{~min}$, starting $20 \mathrm{~min}$ after the gabazine injection, to assure the diffusion of gabazine throughout the $\mathrm{CN}$. The data on GSWD-occurrence following gabazine injection from 4 out of the 6 mice have been reported previously (cf. Fig. 2 in Ref. [15]).

\section{Immunohistochemistry}

Animals were anesthetized with pentobarbital $(0.15 \mathrm{~mL}$, intraperitoneal) and perfused transcardially with saline followed by $4 \%$ paraformaldehyde (Sigma-Aldrich) in $0.1 \mathrm{M}$ phosphate buffer (Sigma-Aldrich, pH 7.4) as previously described [15]. See for further information Suppl. Material and Methods.

\section{Quantification and statistical analysis}

\section{Offline GSWD and extracellular action potential analysis}

Extracellular recordings and spontaneous GSWD characteristics were analyzed offline using previously described methods [15]. In brief, action potential analysis was performed using the customwritten Matlab-based program SpikeTrain (Neurasmus, Erasmus MC Holding, Rotterdam, the Netherlands). Extracellular recordings were included if activity was stable for at least $100 \mathrm{~s}$. GSWD analysis was performed using a custom-written GSWD detection algorithm (LabVIEW, National Instruments, Austin, TX, USA). Coefficient of variance $(\mathrm{CV})$ was calculated as the ratio between the mean and the standard deviation of the interspike intervals $\left(\sigma_{\mathrm{ISI}} / \mu_{\mathrm{ISI}}\right), \mathrm{CV} 2$ as $(2 \mid$ $\left.\operatorname{ISI}_{n+1}-\operatorname{ISI}_{n} \mid /\left(\operatorname{ISI}_{n+1}+\operatorname{ISI}_{n}\right)\right)$ [25] and burst index as BI = number of action potentials within bursts/total number of action potentials) 
A
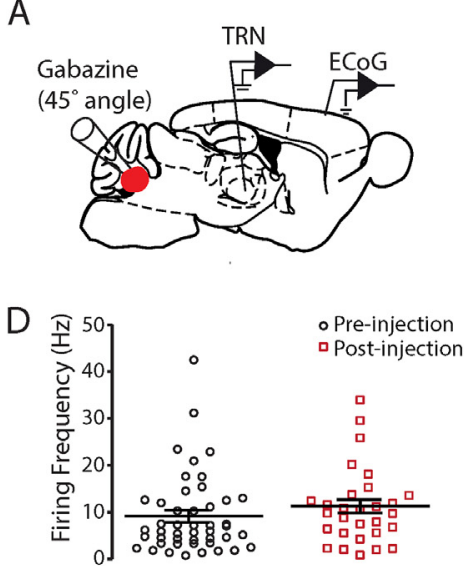

$E$

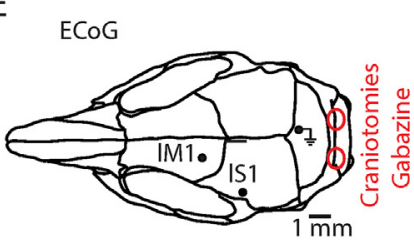

$\mathrm{H}$

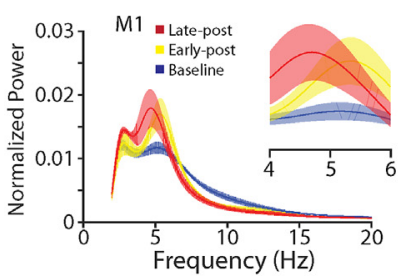

B
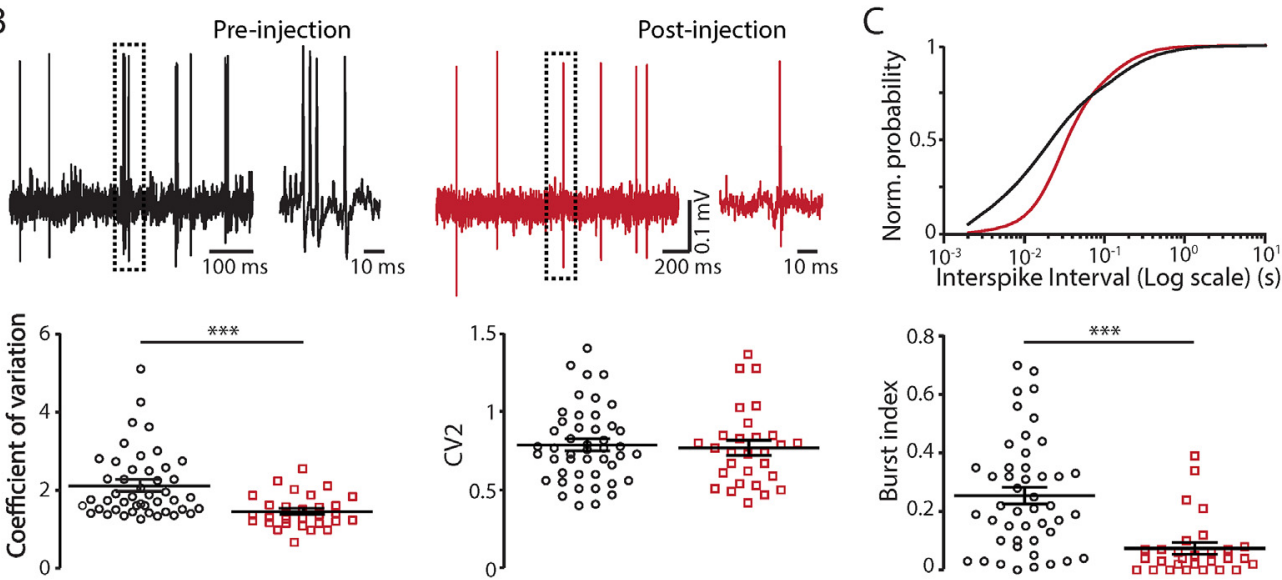

$\mathrm{F}$

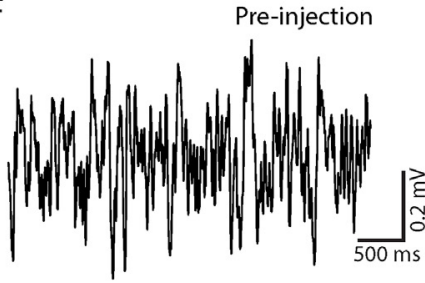

Post-injection

G

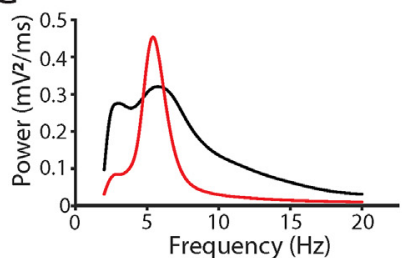

I
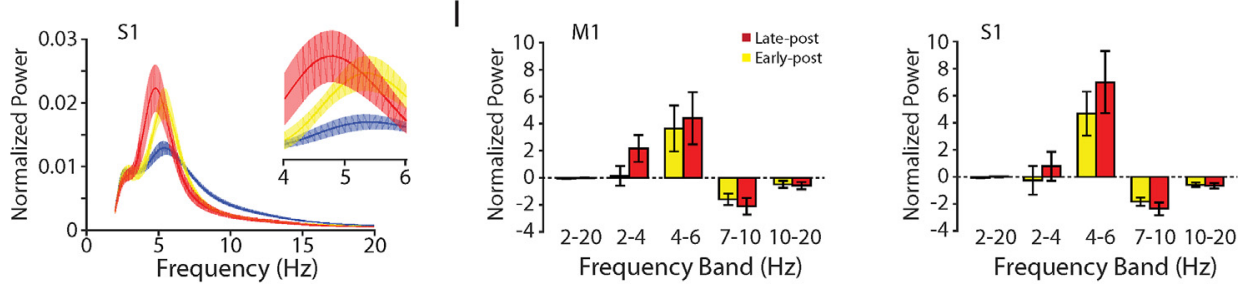

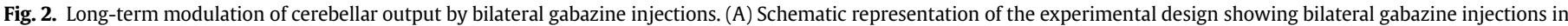

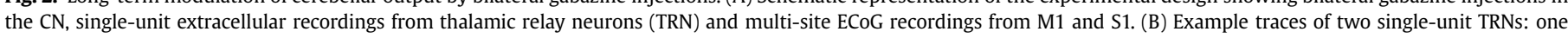

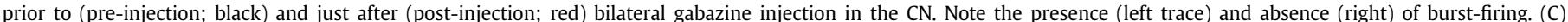

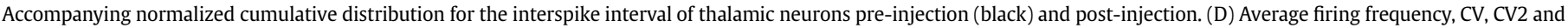

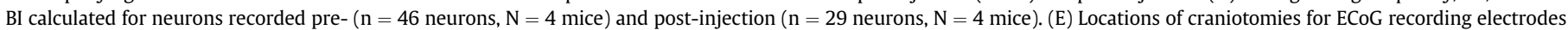

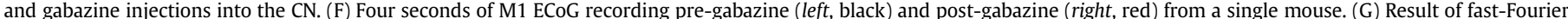

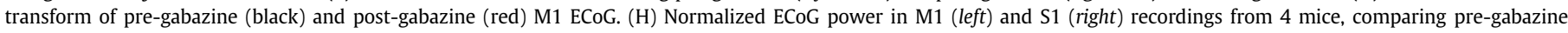

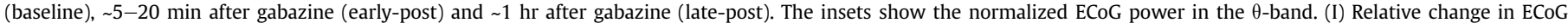

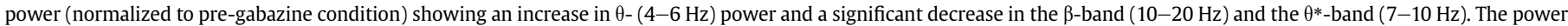

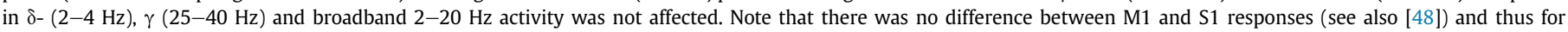

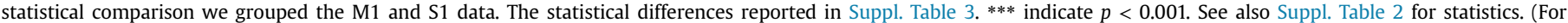
interpretation of the references to color in this figure legend, the reader is referred to the Web version of this article.)

for which we defined 'burst' as a sequence of $\geq 3$ spikes within $100 \mathrm{~ms}$.

\section{Offline multi-unit activity analysis}

Multi-unit activity (MUA) data were analyzed using the template-matching method for spike sorting with an optimal spike threshold of 3X SD from a 60-s baseline recording. Sorted spikes were exported and analyzed following a custom-written algorithm in MATLAB to generate spike histograms. The spike-to-spike correlation (autocorrelation) was calculated based on a previous method [26]. Data points $(x)$ were normalized $\left(X_{S}\right)$ in a $(0,1)$ range using the maximum and minimum spike count $\left(\mathrm{x}_{\max }, \mathrm{x}_{\min }\right): X_{s}=x$ $x_{\min } / x_{\max }-x_{\min }$. Mean correlation values were calculated by taking the ratio of the maximum correlation and the value at $t=0$. The same time range was used to determine the maximum correlation in baseline and post-stimulation. Trials including seizures that ended $-10 \mathrm{~ms}$ before stimulation and $150 \mathrm{~ms}$ after stimulation were not analyzed.

\section{Assessment of modulation of TRN units}

GSWD triggered raster plots and peri-stimulus-time-histograms (PSTHs; 5-ms bin-width) were used to calculate the modulation amplitude and frequency. ISIs of the data used for the raster plots were subsequently shuffled randomly $500 \mathrm{X}$ to create a normal distribution of modulation amplitudes. Cells were considered GSWD-modulated if the modulation amplitude was significantly higher than expected by chance, as indicated by a $\mathrm{Z}$-score $(\mathrm{Z}=(\mathrm{X}-\mu) /$ $\sigma ; Z \geq 1.96, p \leq 0.05)$ using the shuffled data as described previously [15], and if cells modulated at seizure frequency $(6-9 \mathrm{~Hz})$. The phase difference between the occurrence of the most negative deflection of a GSWD-episode and the time of the peak in thalamic activity was calculated by dividing this time difference by the median time difference between GSWDs in that particular seizure. Note that our analysis script identifies the GSWDs, then isolates ECoG spikes and finally quantifies the relative timing between the ECoG spike and thalamic action potentials. In case there are no action potentials fired, the ECoG spike is discarded for further analysis. 

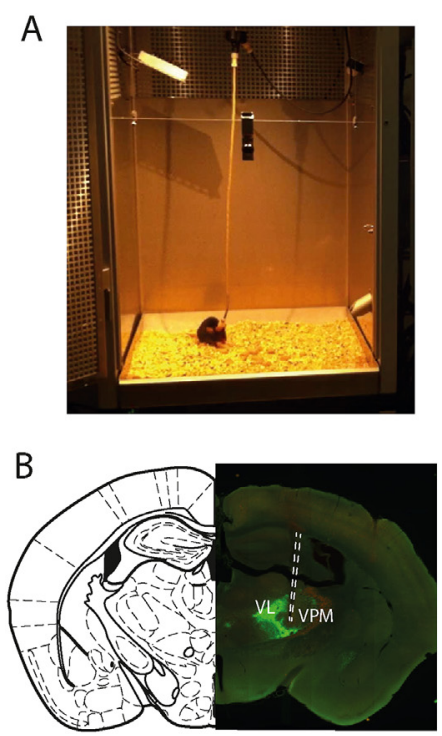

C
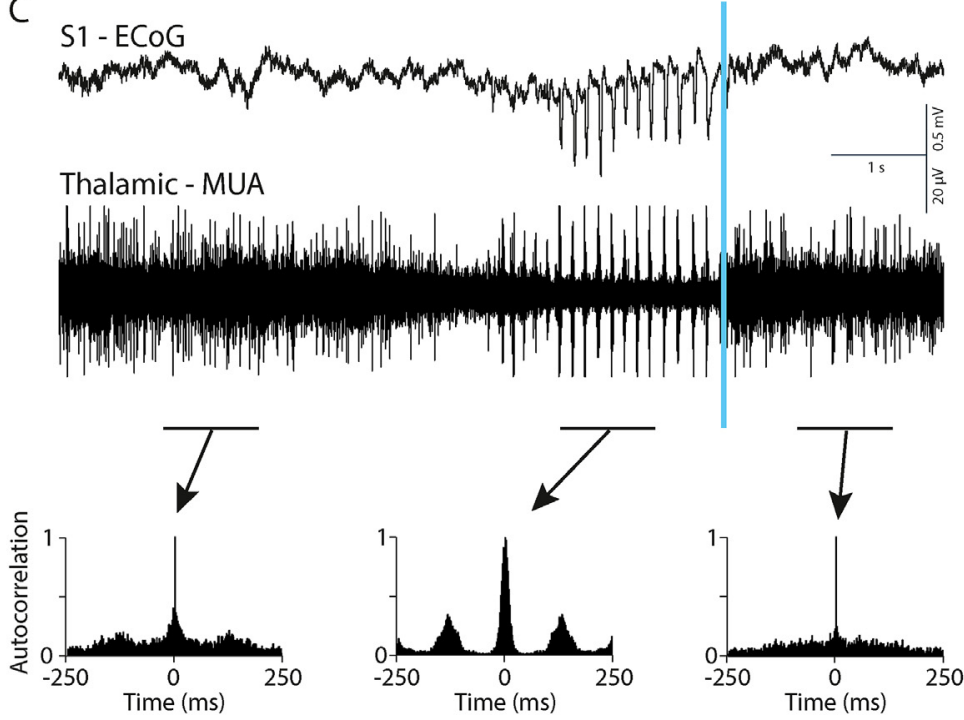

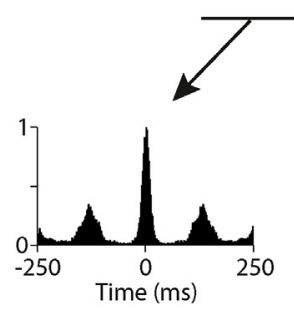

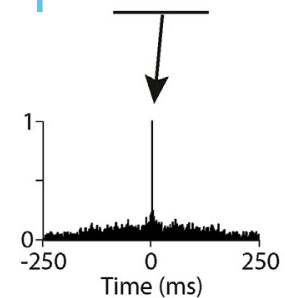
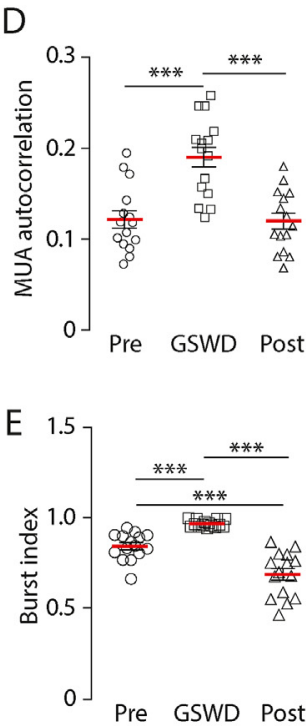

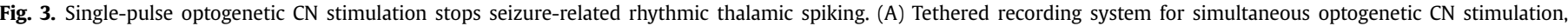

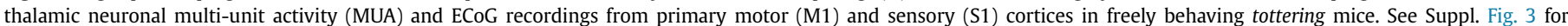

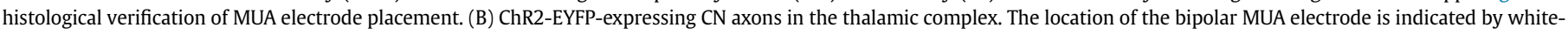

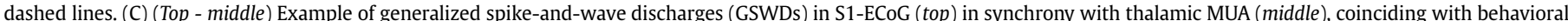

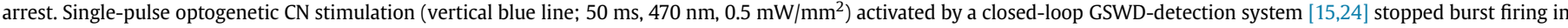

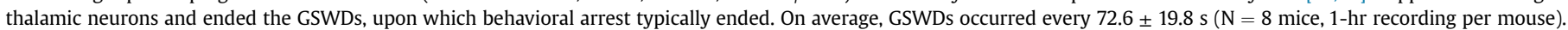

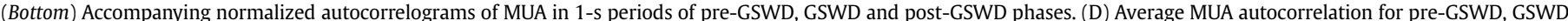

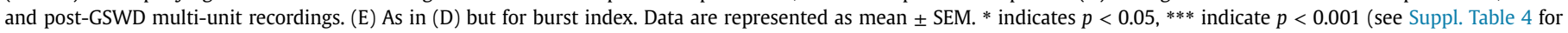
statistics). (For interpretation of the references to color in this figure legend, the reader is referred to the Web version of this article.)

\section{Electrophysiological response to optogenetic stimulation}

To determine if thalamic single units showed a significant response to optogenetic $\mathrm{CN}$ stimulation, we performed a random permutation calculation following a Monte-Carlo Bootstrap method, using 2-ms bin-width PSTHs. For every recording we calculated the ISIs of action potentials $4 \mathrm{~s}$ prior to every pulse and combined them in a single ISI distribution, which was randomly permutated 250 times. We created PSTHs from these 'fake' spike times and calculated the average and standard deviation. If the PSTH of the 'true' spiking response to optogenetic stimuli exceeded the mean \pm 2 SD threshold we noted the recording to have an increased firing response. For a subset of neurons we noticed a compelling inhibition. We marked the recording as showing an inhibitory response if at any time during the post-stimulus period ( $5 \mathrm{~s}$ in total) the spike count was zero for at least 25 consecutive bins, i.e. $50 \mathrm{~ms}$.

\section{Statistical analysis}

We examined the degree of normality of distributions and equality of variances in each group using Kolmogorov-Smirnov and Shapiro-Wilk's tests. We analyzed the data using parametric (paired $t$-tests, (repeated measures) ANOVAs or MANOVAs) or nonparametric tests (Kruskal Wallis tests, Mann-Whitney U tests or Friedman ANOVA's) depending on whether data were normally distributed and variances equal. Tamhane and Bonferroni corrections were used in case of multiple non-independent variables. For the ECoG data, statistical analysis of the power in each frequency band was carried out using repeated measures ANOVAs with time point ('Baseline', 'Early-Post' and 'Late-Post') as the within-subject factor and recording location as the between subject factor. Only frequency bands that displayed a significant main effect of time point were subjected to post-hoc paired $t$-tests. Two tailed testing was used in all analyses and a $p$-value $\leq 0.05(\alpha)$ was considered significant. A single asterisk indicates $p<0.05$, two asterisks indicate $p<0.01$, and three asterisks indicate $p<0.001$. Details of each statistical test performed are given in Supplementary Tables.

\section{Data availability}

Further information and requests for data, resources and reagents should be directed to the corresponding author, Freek E. Hoebeek (f.e.hoebeek@umcutrecht.nl).

\section{Results}

Subportion of thalamic firing is rhythmic and synchronized with cortical GSWDs

Recently, we showed that optogenetic stimulation of CN neurons effectively stops generalized seizures in mouse models, implying that the $\mathrm{CN}$ may be a novel therapeutic target for brain stimulation for refractory epilepsy in patients [15]. To enable an indepth investigation of mechanisms underlying this therapeutic effect, we simultaneously recorded individual thalamic neurons and cortical ECoG in awake head-fixed homozygous tottering mice. We first studied their regular seizure-related activity in the thalamic nuclei that are known to receive $\mathrm{CN}$ projections. Cortical GSWDs, characteristic of absence epilepsy, were detected in the ECoG signals when a seizure occurred. In this setup, seizures lasted $3.05 \pm 1.00 \mathrm{~s}$ and consisted of repetitive ECoG spikes at $8.40 \pm 0.71 \mathrm{~Hz}(\mathrm{~N}=8$ mice $)$, which is comparable to previous studies in tottering mice $[15,19,27,28]$. Recording sites of thalamic neurons ( $\mathrm{n}=70$ neurons; $\mathrm{N}=8$ mice) were labeled using iontophoretic injections of biocytin (Fig. 1A and B). From an additional 52 thalamic neurons (identified by their firing characteristics) we did not label the recording site. Out of the in total 122 thalamic neurons, $68(55,7 \%)$ showed firing that was phase-locked to GSWDs (Fig. 1C and D; Suppl. Fig. 1; Suppl. Table 1). The compiled spiking 
A

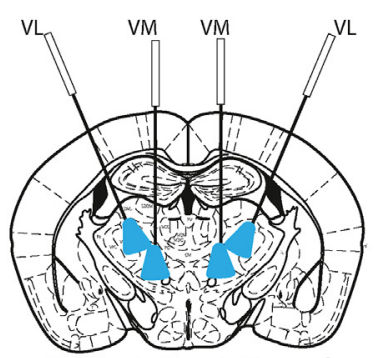

Optical stimulation of

$\mathrm{CN}$ axons in thalamus
B

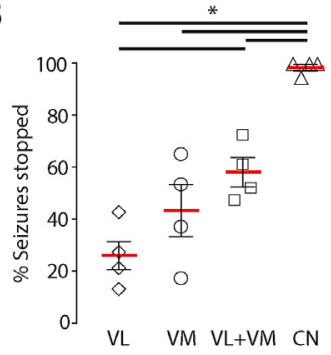

Bilateral stim $(50 \mathrm{~ms})$
C

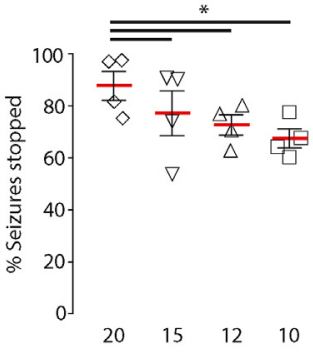

Bilateral CN stim (ms)
D

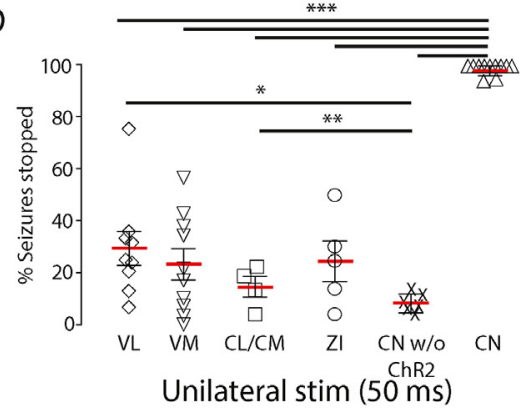

E

VL
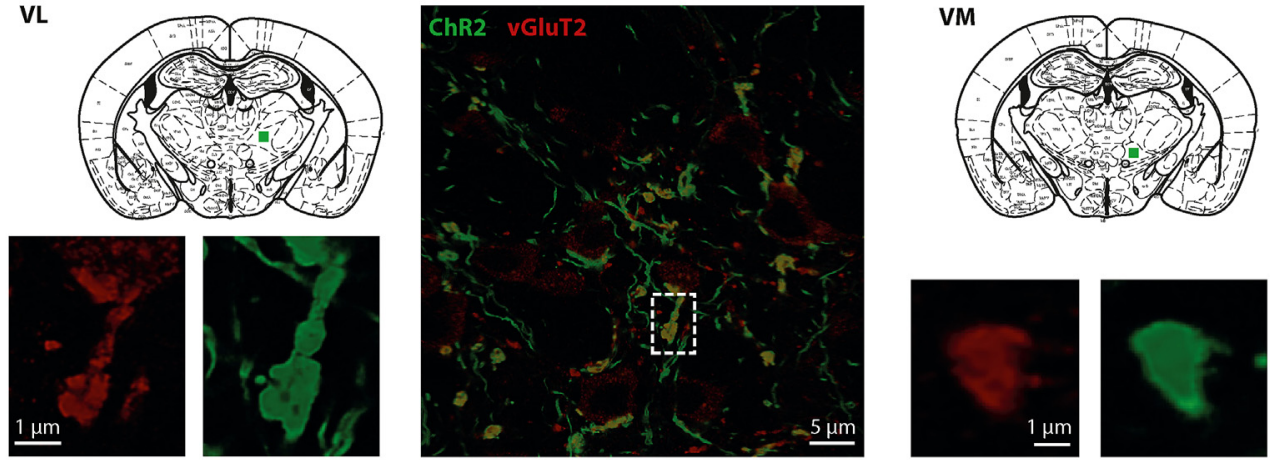

ZI
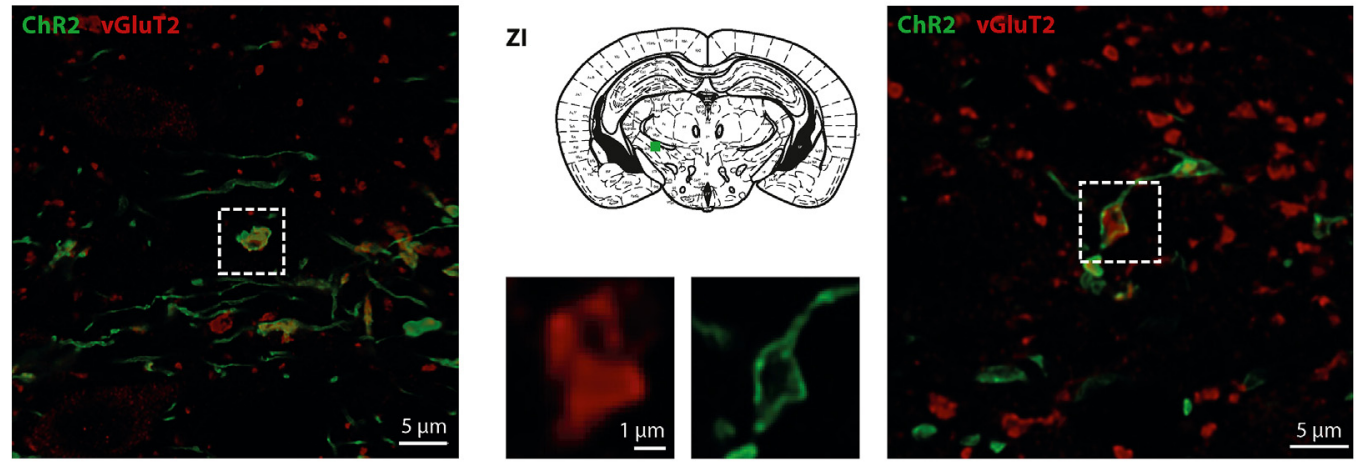

F
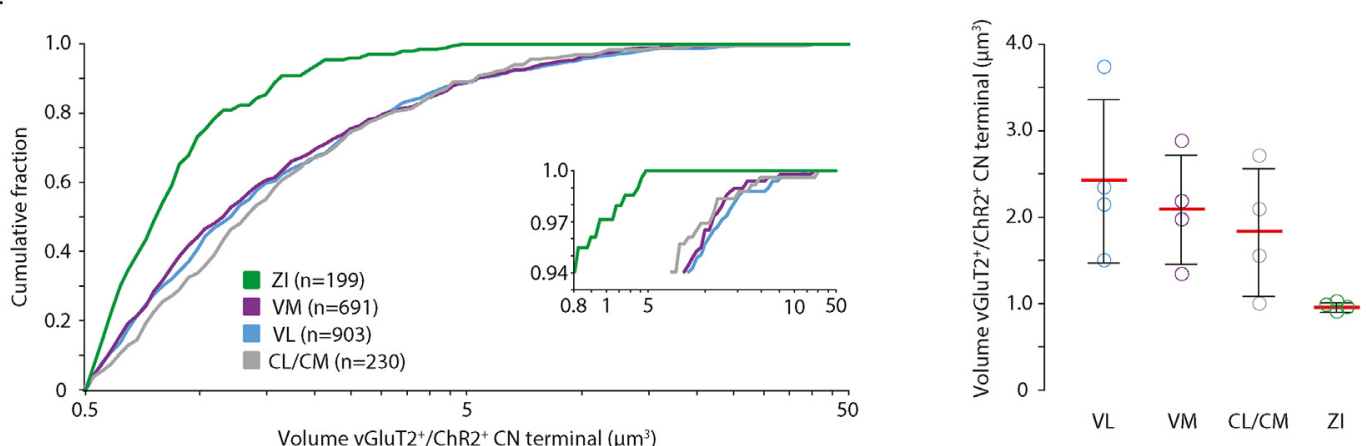

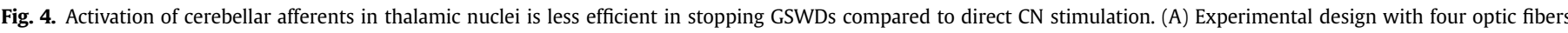

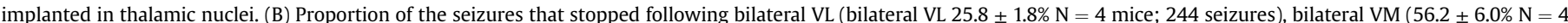

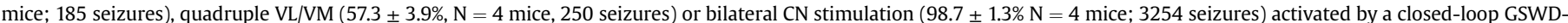

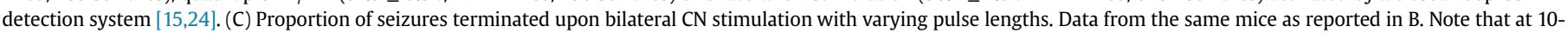

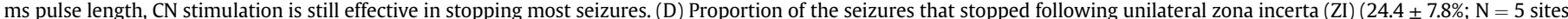

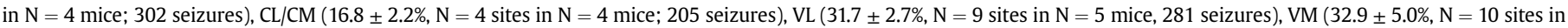

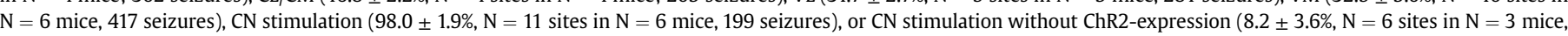


activity per nucleus shows that the phase difference between the thalamic modulation peak and ECoG spike is remarkably consistent across nuclei (Fig. 1E). Of note is that often ECoG spikes were not accompanied by thalamic action potential firing.

Pharmacologically increasing $C N$ activity reduces thalamic burst firing and power in ECoG frequency bands

Our previous findings indicate that blocking GABAergic transmission in the $\mathrm{CN}$, which increases firing frequency and regularity, decimates seizure occurrence in tottering and $\mathrm{C} 3 \mathrm{H} / \mathrm{HeOuJ}$ mice [15]. To further unravel the impact of modifying $\mathrm{CN}$ output on thalamic firing activity, we investigated the effects of gabazine infusion in the $\mathrm{CN}$ of tottering mice on interictal thalamic firing patterns and ECoG signals. Single-unit thalamic recordings indicated that bilateral infusion of gabazine in $\mathrm{CN}$ significantly increased the spiking regularity (CV-pre: $2.12 \pm 0.12$ vs. CV-post: $1.46 \pm 0.08 ; p<0.001$; BI-pre: $0.25 \pm 0.03$ vs BI-post: $0.07 \pm 0.02 ; p<0.001)$, but did not alter the firing frequency $(9.1 \pm 1.3 \mathrm{~Hz}$ vs. $11.0 \pm 1.5 \mathrm{~Hz} ; p=0.328)$. (Fig. 2A-D; Suppl. Table 2). In parallel, the power of ECoG frequency bands showed significant changes mediated upon pharmacological manipulation of $\mathrm{CN}$ firing (Fig. $2 \mathrm{E}-\mathrm{G}$ ). Most notably, the power of ECoG frequencies in the seizure-related high-theta band $\left(\theta^{*}\right.$; $7-10 \mathrm{~Hz}$ ) was significantly decreased, whereas it was increased in the low-theta band $(\theta ; 4-6 \mathrm{~Hz})$ in both $\mathrm{M} 1$ and $\mathrm{S} 1$ (Fig. $2 \mathrm{H}$ and I; Suppl. Table 3). Together these data indicate that long-lasting increases in $\mathrm{CN}$ regularity and firing frequency increases the regularity of thalamic neurons and dampens ECoG activity in seizurerelated frequency bands during interictal periods.

\section{Optogenetic $C N$ stimulation reduces thalamic synchronization and burst firing}

Next, we determined how short-lasting, single pulses of optogenetic $\mathrm{CN}$ stimulation affect thalamic firing during GSWDs. For this, we used MUA recordings of thalamic neurons in freely moving tottering mice, which showed that the rhythmicity of thalamic action potential firing was increased during GSWDs compared to interictal periods and that these oscillations were phase-locked to the ECoG spikes (Fig. 3A-C). Visual inspection of tottering mice showed that during GSWDs the mice were immobile. The average occurrence of GSWDs in this freely behaving setup was $18.9 \pm 1.9$ per $\mathrm{hr}$ and the average duration per episode was $2.33 \pm 0.19 \mathrm{~s}$. To apply optogenetic stimulation we infected $\mathrm{CN}$ neurons with ChR2 via AAV injections and implanted optical fibers to excite these neurons with $470 \mathrm{~nm}$ light pulses $\left(0.5 \mathrm{~mW} / \mathrm{mm}^{2}\right)$ of $50-\mathrm{ms}$ (see Suppl. Fig. 2 for topographic mapping of ChR2-expressing CN neurons). Such optical stimulation during seizures (see Fig. 3 in Ref. [15] for controls) often triggered exploratory behavior while the phase-locked thalamic MUA was instantly reverted into a desynchronized state without rhythmic MUA bursts, as shown by a significant reduction in the peak of the MUA autocorrelogram (MUA-autocorrelation-Pre: $0.12 \pm 0.01$; MUA-autocorrelationGSWD: $0.19 \pm 0.01$; MUA-autocorrelation-Post: $0.12 \pm 0.01$; Pre vs. Post $p=0.80$; all other comparisons $p<0.001$; Fig. $3 C$ and $D$;
Suppl. Fig. 3 for location of thalamic MUA electrodes; Suppl. Table 4). Likewise thalamic BI values significantly increased during GSWDs and decreased upon $\mathrm{CN}$ stimulation (BI-Pre: $0.85 \pm 0.02$; BI-GSWD: $0.97 \pm 0.01$; BI-Post: $0.69 \pm 0.03$; all comparisons $p<0.001$; Fig. 3E; Suppl. Table 4). These findings indicate that single-pulse, yet conjunctive stimulation of the $\mathrm{CN}$ neurons desynchronizes seizure-related rhythmic thalamic MUA.

\section{Stimulation of CN neurons is more effective in stopping GSWDs than activation of sets of $\mathrm{CN}$ axons within thalamus}

$\mathrm{CN}$ axons synapse divergently throughout various nuclei of the thalamic complex of wild type rodents $[16,18,29]$. To confirm the projection patterns in tottering mice, we qualitatively evaluated the location of ChR2-expressing CN axons and found EYFP fluorescence in VL and VM, but also the CL, CM and ZI nuclei (Suppl. Information related to Fig. 4) alike wild type mice. To investigate whether stimulation of cerebellar afferents in thalamic nuclei is as effective in stopping GSWDs as direct stimulation of the $\mathrm{CN}$, we implanted optic fibers in different nuclei of the thalamic complex of headfixed tottering and optogenetically stimulated the local $\mathrm{CN}$ axons (see Suppl. Fig. 2 for topographic mapping of ChR2-infected CN neurons). We initially focused on VL and VM, i.e., the thalamic nuclei with the highest level of fluorescence evoked by AAV-ChR2EYFP expressing CN axons (VL: $47.5 \pm 11.2$ arbitrary units (a.u.); VM: $54.5 \pm 14.0$ a.u.; $\mathrm{N}=5$ mice). Given that VL and VM not only innervate M1, but also prefrontal, sensory and associative cortical regions [30,31], we hypothesized that selectively stimulating CN axons in these nuclei would be sufficient to stop all GSWDs.

Using our previously published closed-loop GSWD detection system $[15,32]$ we drove the optical stimulation and found that bilateral optogenetic stimulation of cerebellar afferents in VL or VM stopped only a portion of the seizures (VL: $26.2 \pm 6.3 \%$ seizures stopped; VM: $43.4 \pm 10.4 \%$; see Suppl. Table 5 for number of seizures analyzed per animal; Fig. 4A and B). In an attempt to increase the efficacy of seizure termination we activated all thalamic optic fibers simultaneously, which was more effective (VL + VM: $58.5 \pm 5.5 \%$ seizures stopped; VL vs. VL + VM $p<0.05$ ), but still significantly less effective than $\mathrm{CN}$ stimulation $(98.7 \pm 1.3 \%$; all comparisons $p<0.05$ ) (Fig. 4B; Suppl. Information; Suppl. Table 6). Even when we decreased the pulse length in steps to $10 \mathrm{~ms}$, the efficacy of direct CN stimulation in stopping GSWDs $(71.4 \pm 6.8 \%$ for 10 -ms stimulation) was at least as high as when applying $50-\mathrm{ms}$ pulses to the VL and VM optic fibers simultaneously (Fig. 4B and C; Suppl. Table 6). As additional controls, we also implanted fibers in the zona incerta and in the intralaminar CL and CM nuclei, all of which may also influence cortical seizure activity $[33,34]$ and in the $\mathrm{CN}$ of mice injected with an AAV-EYFP construct. Optical stimulation of ChR2-expressing $\mathrm{CN}$ axons with $50 \mathrm{~ms}$ pulses of $470 \mathrm{~nm}$ in unilateral $\mathrm{CL} / \mathrm{CM}$ and zona incerta was not as effective as unilateral stimulation of $\mathrm{CN}$ neurons (all comparisons $p<0.001$ ) and proved only marginally better than $\mathrm{CN}$ stimulation in the absence of $\mathrm{ChR} 2$ (Fig. 4D; Suppl. Information; Suppl. Table 6). To investigate the size of the $\mathrm{CN}$ axon terminals in these thalamic nuclei we next used immunofluorescent staining for vesicular glutamate transporter

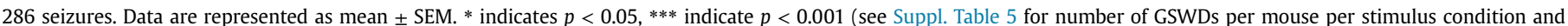

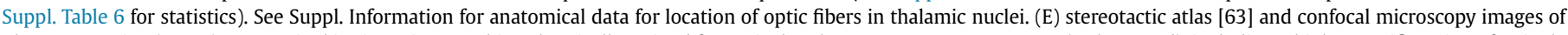

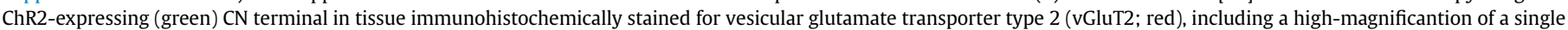

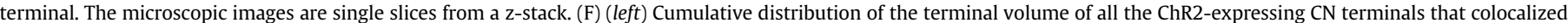

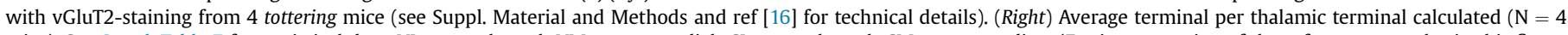

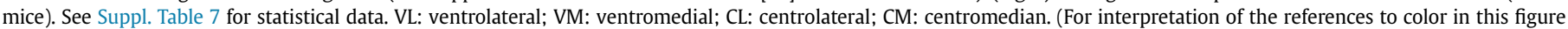
legend, the reader is referred to the Web version of this article.) 
A

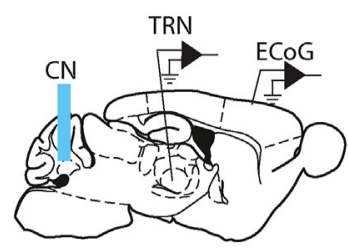

B

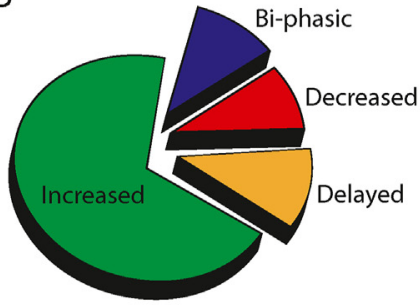

C
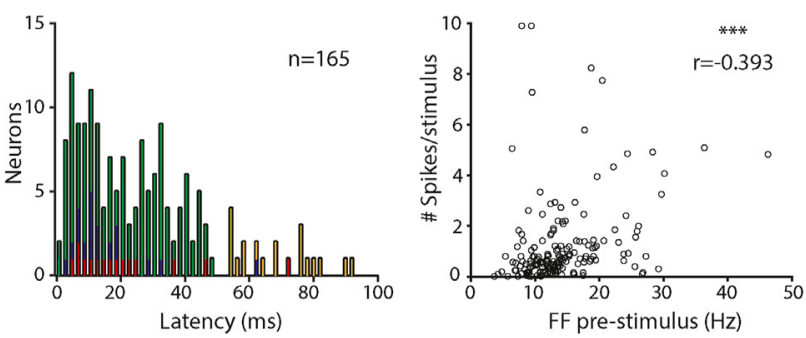

E
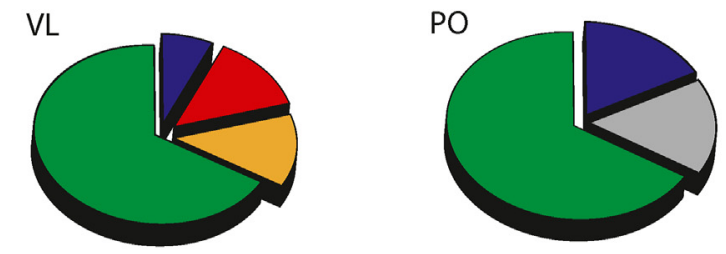

$\square$ Biphasic

$\square$ Increased

$\square$ Delayed

$\square$ Decreased

vв

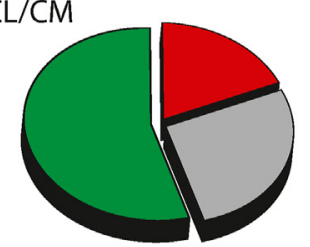

$\square$ No response

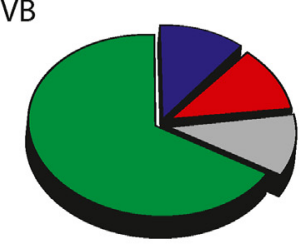

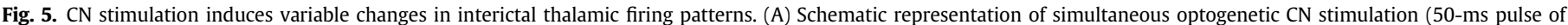

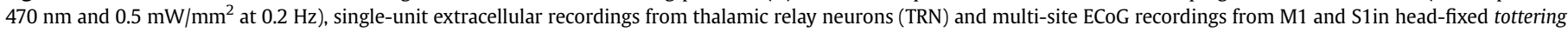

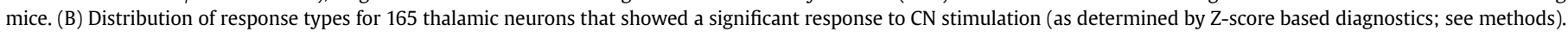

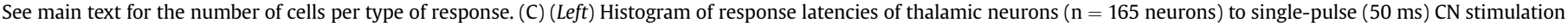

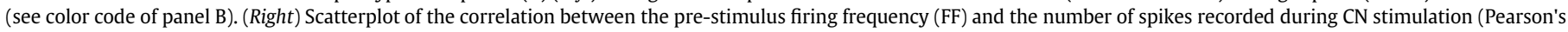

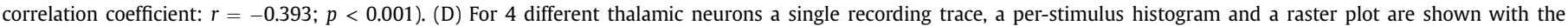

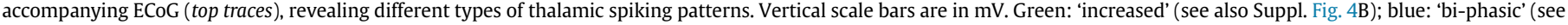

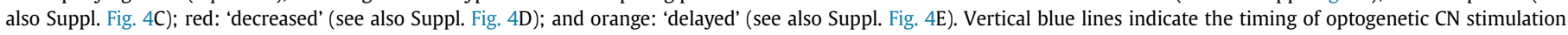

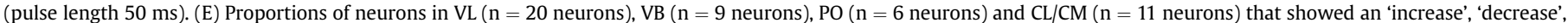

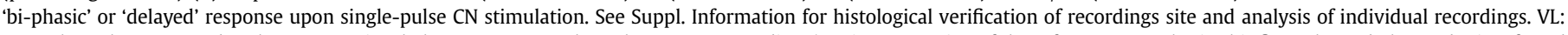

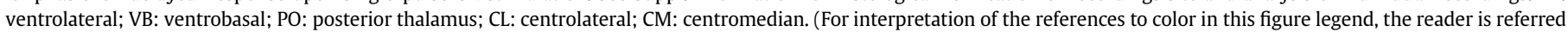
to the Web version of this article.)

type 2 (vGluT2). For 4 mice we labeled coronal sections with vGluT2 and calculated the volume of the vGluT2-positive ChR2expressing $\mathrm{CN}$ axon terminals (Fig. 4E; see Suppl. Material and Methods). This morphological reconstruction indicated that the size of the $\mathrm{CN}$ terminals in tottering mice ranges widely throughout VL, VM, CL/CM and ZI (Fig. 4F). We found that the smallest terminals, which often appeared 'en passant' type, are located in ZI $\left(0.96 \pm 0.05 \mu^{3} ; 199\right.$ terminals from 4 mice) compared to VL $\left(2.42 \pm 0.95 \mu \mathrm{m}^{3}\right.$; 903 terminals from 4 mice $), \mathrm{VM}\left(2.09 \pm 0.63 \mu \mathrm{m}^{3}\right.$; 691 terminals from 4 mice $)$ and $\mathrm{CL} / \mathrm{CM}\left(1.83 \pm 0.73 \mu \mathrm{m}^{3} ; 230\right.$ terminals for 4 mice) ( $p=0.08$, MANOVA; see Suppl. Table 7). Collectively, these data indicate that direct optogenetic stimulation of $\mathrm{CN}$ is a more efficient in stopping seizures than stimulating a portion of $\mathrm{CN}$ axons and their variably sized axon terminals within the thalamic nuclei.

\section{Stimulation of CN neurons induces heterogeneous effects in thalamus during interictal periods}

To investigate the heterogeneity of the effects of $\mathrm{CN}$ stimulation on thalamic activity, we next set out to record single-unit thalamic neurons and evaluate the responses to $\mathrm{CN}$ stimulation during interictal periods (Fig. 5A; see Suppl. Fig. 2 for topographic mapping of cerebellar optic fibers). Out of 201 recorded neurons, 165 neurons were responsive to single-pulse $\mathrm{CN}$ stimulation with variable response latencies and types of responses (Fig. 5B-D; Suppl. Fig. 4; Suppl. Table 8). Upon CN stimulation 114 out of 165 neurons (69.1\%) significantly increased their firing rate (group 'increased'; onset latency $21.3 \pm 1.3 \mathrm{~ms}$; duration response $47.0 \pm 4.6 \mathrm{~ms}$ ). Of these 114 cells, 24 showed a persisting effect (duration response: $94.7 \pm 12.9 \mathrm{~ms}$ ). Eighteen thalamic neurons (out of $165 ; 10.9 \%$ ) responded in a bi-phasic manner, i.e., an initial increased firing rate followed by a significantly decreased firing rate (group 'bi-phasic'; onset latency increased phase: $15.5 \pm 3.5 \mathrm{~ms}$; duration response: $28.1 \pm 3.7 \mathrm{~ms}$; onset latency decreased phase: $60.2 \pm 6.1 \mathrm{~ms}$; average length of decrease of $196 \pm 56 \mathrm{~ms}$ ). A third cluster of 15 thalamic neurons (9.1\%) only showed a decrease in firing rate upon CN stimulation (group 'decreased'; onset latency $20.6 \pm 4.8 \mathrm{~ms}$; length: $171 \pm 51 \mathrm{~ms}$ ). Finally, 18 recorded neurons (10.9\%) did not show any significant change in firing rate during the 50-ms stimulus, but only thereafter (group 'delayed'; onset latency $68.4 \pm 2.9 \mathrm{~ms}$; length: $85.5 \pm 9.3 \mathrm{~ms}$ ). Interestingly, the number of spikes that was induced during an optogenetic pulse correlated negatively with the pre-stimulus firing frequency (Fig. 5C). Post hoc immunohistochemical analysis of the recording locations revealed that the individual nuclei in the thalamus all showed at least two 
different types of responses (Fig. 5E; Suppl. Information). These findings indicate that $\mathrm{CN}$ stimulation evokes remarkably variable thalamic responses that are not restricted to a particular thalamic nucleus.

To find out how desynchronizing thalamic firing upon $\mathrm{CN}$ stimulation may translate into changes in cerebral cortical activity, we further analyzed the simultaneously recorded M1 and S1 ECoG activity (Fig. $6 \mathrm{~A}$ ). $\mathrm{CN}$ stimulation during interictal periods induced a large amplitude ECoG peak with high power in lower frequency bands (Suppl. Fig. 5). To optimize ECoG analysis during the poststimulus period, we replaced the $\mathrm{CN}$-evoked ECoG peak with baseline ECoG data (see 'Interictal ECOG Analysis' in Suppl. Material and Methods section). Hereby, we avoided any dominant effect of the CN-evoked low-frequency peak on the ECoG spectrogram, which lasts for a prolonged period of time (Suppl. Fig. 3) [15,35]. This replacement revealed that single-pulse $\mathrm{CN}$ stimulation during interictal periods resulted in a prolonged decrease in nearly all frequency bands (Fig. 6B-D; Suppl. Table 9). These data also showed that within the $\theta^{*}$-band $(7-10 \mathrm{~Hz})$, which corresponds to the frequency band most dominantly increased during absence seizures [36], power significantly reduced in $\sim 40 \%$ of the trials - an effect seen at all recorded cortices (rM1: $39.9 \pm 6.8 \%$; $1 \mathrm{M} 1$ : $40.4 \pm 6.3 \%$; IS1: $40.4 \pm 7.0 \%$ ) in average responses and power spectrograms (Fig. 6C and D). Together, our data during interictal periods highlight the possibility that variability of thalamic responses to $\mathrm{CN}$ stimulation facilitates the desynchronizing effect of the $\mathrm{CN}$ on thalamic activity during seizures and that this impact can transverse towards the cerebral cortex.

\section{Discussion}

Using a combination of electrophysiology, pharmacology and optogenetics, we showed that $\mathrm{CN}$ stimulation elicits heterogeneous effects throughout the complex of thalamic nuclei in tottering mice, a well-established genetic model for generalized absence epilepsy $[19,37]$. Activation of the cerebello-thalamic pathway during seizures in tottering mice resulted in desynchronization of ictal thalamic activity. Moreover, increasing the regularity and firing frequency of $\mathrm{CN}$ neurons by pharmacological blockage of inhibitory input in the cerebellum (c.f., Fig. 2C in Ref. [15]) decimated thalamic burst firing without changing the average thalamic firing frequency and stopped the occurrence of GSWDs. Comparing the inter-ictal ECoG before and after cerebellar gabazine infusion revealed that indeed the power at the frequency range of $7-10 \mathrm{~Hz}$ was decreased. Given that short-lasting $\mathrm{CN}$ stimulation during interictal periods had a variety of effects on thalamic spiking, but still reduced the ECoG power at $7-10 \mathrm{~Hz}$, these results indicate that cerebellar output is of relevance for controlling thalamo-cortical synchronicity in the frequency band of absence seizures.

Our multi- and single-unit recordings in tottering mice demonstrated that thalamic action potential firing is prominently phase-locked to GSWDs, which is in line with earlier reports on cellular excitability and hypersynchronicity in thalamo-cortical networks [38-41]. Single-unit recordings in primary, associative and intralaminar thalamic nuclei showed that $\sim 50 \%$ of the neurons fire most action potentials $\sim 20 \mathrm{~ms}$ prior to the peak of the ECoG spikes during GSWD episodes. In other rodent models of absence epilepsy the distribution of this delay also is rather narrow, ranging from $9 \mathrm{~ms}$ in a genetic rat model for absence epilepsy (GAERS) to $28 \mathrm{~ms}$ in Long-Evans rats $[42,43]$. Notably, we found that 54 of the 122 recorded thalamic neurons did not show significant modulation of their spiking pattern during GSWD episodes, which might be due to a decreased action potential firing in thalamus during GSWDs, as was previously highlighted in the GAERS model $[44,45]$.

We found that long-lasting pharmacological blockage of local GABA-mediated transmission was effective in dampening the occurrence of GSWDs, but without affecting the average firing frequency of thalamic neurons. This absence of an effect on the thalamic spiking frequency appears counterintuitive in view of the increased firing frequency of $\mathrm{CN}$ neurons following local gabazine injections [15]. Although future experiments should investigate the underlying mechanism, two factors may contribute to the steady firing frequency of thalamic neurons during cerebellar pharmacological manipulations: (1) thalamic neurons receive inhibitory input from intrathalamic reticular and extrathalamic mesencephalic nuclei [46], which in principle could balance the impact of an
A

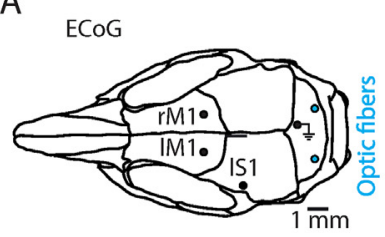

C

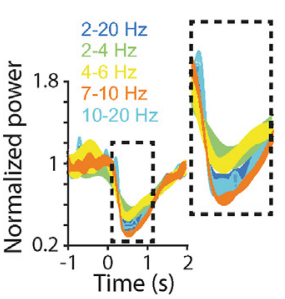

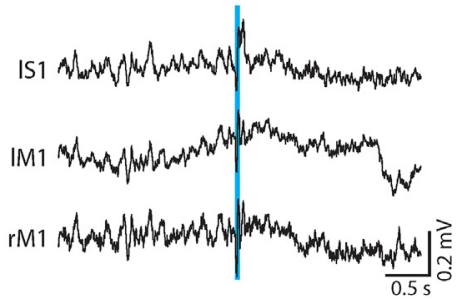

IM1
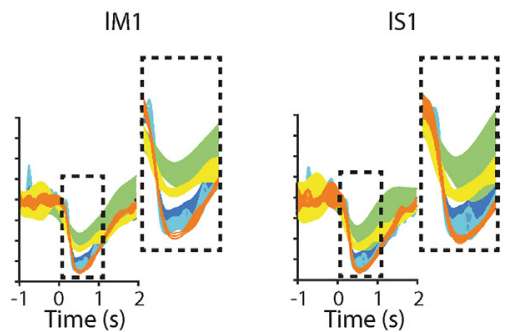

B

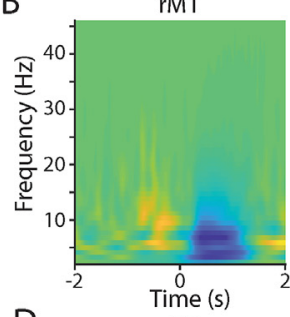

$\mathrm{D}$
IM1

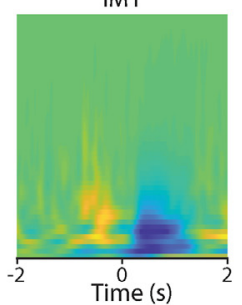

IM1

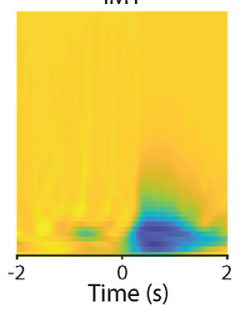

|S1

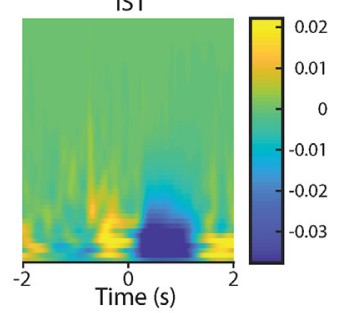

$|S|$

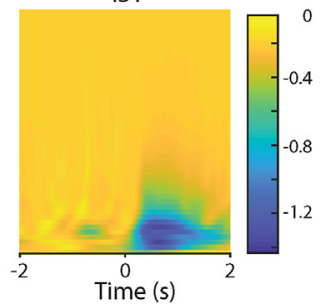

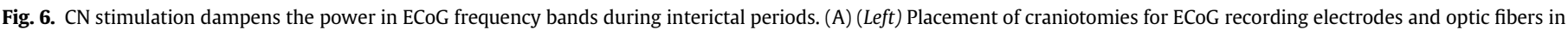

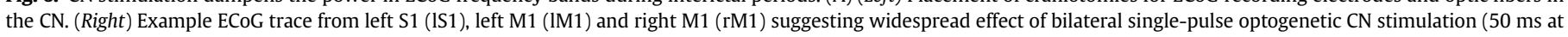

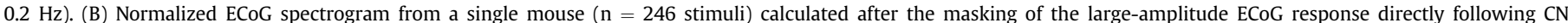

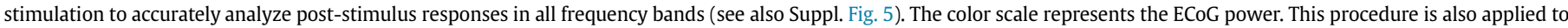

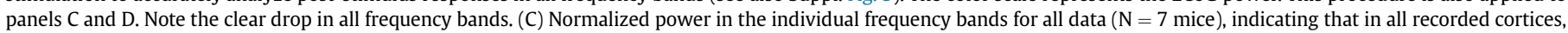

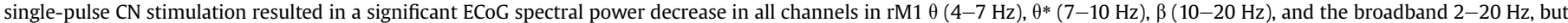

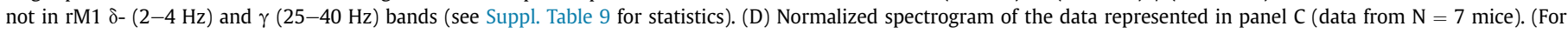
interpretation of the references to color in this figure legend, the reader is referred to the Web version of this article.) 
increased $\mathrm{CN}$ firing frequency on the thalamic firing pattern; and (2) $\mathrm{CN}$-thalamic synapses are excitatory, but have been shown in wild type rodents to be subject to paired-pulse depression when stimulated repetitively (e.g. Refs. $[16,47])$. It might be that the P601L loss-of-function mutation in Cav2.1 (P/Q-type) $\mathrm{Ca}^{2+}$ channels [37] weakens the synaptic transmission at $\mathrm{CN}$-thalamic synapses and thereby contributes to the lack of impact of cerebellar gabazine infusions on thalamic firing frequency.

In our multi-unit recordings in freely behaving tottering mice we noticed that the peaks in thalamic firing during GSWDs, which highlight synchronous action potential firing, were dampened following optogenetic $\mathrm{CN}$ stimulation. This desynchronizing effect may be due to the heterogeneity of type, length and amplitude of the thalamic responses. In our head-fixed setup for single-unit recordings we recorded four different types of responses in thalamic firing patterns of which the most commonly recorded one was an increased firing pattern. In addition, a more complex and longer lasting change in firing pattern was recorded in 30\% of the recorded neurons. On average the length of these 'decreased', 'biphasic' and 'delayed' responses outlasted the $50-\mathrm{ms}$ optical stimulation by $>100 \mathrm{~ms}$. This indicates that for $\sim 150 \mathrm{~ms}$ the firing pattern of a substantial portion of thalamic neurons is desynchronized. Since in tottering mice cerebello-thalamo-cortical oscillations occur at $\sim 8 \mathrm{~Hz}$, i.e., with a cycle period of $125-\mathrm{ms}$, our data indicate that the synchronous oscillations of action potential firing and presumably also the membrane potential, are disrupted in $30 \%$ of the thalamic cells that receive $\mathrm{CN}$ input. Moreover, since thalamic depolarization has been proven effective in stopping thalamo-cortical oscillations characteristic of absence seizures in Wistar Albino Glaxo rats from Rijswijk (WAGRij) [48], also the relatively short-lasting 'increased' responses in principle could have a long-lasting effect by stopping the 125 -ms cycle period of thalamic membrane potential oscillations. Finally, we also noted that the differences in amplitude of the responses, i.e., the absolute change in the firing rates, among individual neurons of the different response types are substantial. Given that we found at least two types of responses in neuronal firing in all thalamic nuclei, our data indicate that despite the pure excitatory nature of cerebello-thalamic synapses, neighboring thalamic cells respond variably to $\mathrm{CN}$ stimulation [16,35,47,49-56].

One possible source for the variability in the length and amplitude of the responses might be the fact that we infected neurons with ChR2 in various $\mathrm{CN}$ subregions (including medial, interposed and lateral nuclei) and that it was unavoidable to have some variability in the placement of the optical fibers (see Fig. 5 and Suppl. Fig. 2), thereby activating various neural networks that differentially evoke activity in the thalamus. This possibility is supported by the broad range of strengths that is reported for cerebello-thalamic synapses in wild type VL, VM and CL thalamus [16]. Additionally, the variability in the responses may in part result from the heterogeneous and variable impacts of the various indirect pathways between $\mathrm{CN}$ neurons and the recorded thalamic neurons. Indeed, the indirect projections from the $\mathrm{CN}$ to prethalamic nuclei, such as the middle and deeper layers of the superior colliculus, the zona incerta as well as the anterior pretectal nucleus, may contribute to the variability of thalamic responses to $\mathrm{CN}$ stimulation [17,46]. Moreover, these indirect pathways may, in conjunction with the intra-thalamic inhibitory projections from the reticular thalamic nucleus, explain why electrical CN stimulation can result in bi-modal excitatory-inhibitory responses in thalamus neurons $[55,57,58]$. Finally, it is also possible that excitation of $\mathrm{CN}$ neurons that do not project to thalamus, but rather to premotor nuclei in the brainstem, affect thalamo-cortical synchrony by eliciting proprioceptive signals that are indirectly evoked by motor responses [59-61].
Selective stimulation of a subpopulation of $\mathrm{CN}$ axons within the various thalamic nuclei turned out to be less efficient in stopping absence seizures than direct stimulation in the cerebellar nuclei. This may partially result from incomplete optogenetic control of the widespread $\mathrm{CN}$ terminals in the thalamic nuclei, compared to the direct targeting of localized neurons within the $\mathrm{CN}$. In addition, it may be that the variability in $\mathrm{CN}$ axon terminal volume, which has been shown to be quite pronounced between VL, VM and CL/ $\mathrm{CM}$ and to be linked to the amplitude of post-synaptic responses in wild type mice [16], also contributes to the lower number of seizures that were stopped by optical stimulation of ChR2-expressing $\mathrm{CN}$ axons in thalamic nuclei. Since direct stimulation in $\mathrm{CN}$ was most efficient, this might indicate that simultaneously evoking different activity patterns in multiple $\mathrm{CN}$-thalamic pathways operates as a synergistic tool that via a divergent projection pattern effectively desynchronizes GSWDs.

In conclusion, our data show that targeted stimulation of $\mathrm{CN}$ neurons results in desynchronization of thalamic firing concurring with termination of GSWDs in tottering mice. This identifies the CN as a potentially important node in the neuronal network underlying generalized absence seizures, with potentially promising implications for other types of generalized seizures.

\section{Funding}

This research was supported by funding from ERC-Adv, ERC-PoC to C.I.D.Z., NWO-Veni and Erasmus MC fellowship to L.K., various ZonMw and NWO-ALW grants to A.M.J.M.v.d.M., C.I.D.Z. and F.E.H, FP7 "EUROHEADPAIN" to A.M.J.M.v.d.M. and EU IAPP "BRAINPATH" to A.M.J.M.v.d.M. and E.A.T., EU Marie Curie Career Integration Grant to E.A.T. and the Dutch National Epilepsy Foundation to A.M.J.M.v.d.M. and E.A.T. L.K., E.A.T., A.M.J.M.V.D.M, C.I.D.Z. and F.E.H. are supported by the national medical delta ('Medical Neurodelta)' scientific program, and finally C.I.D.Z. and L.K. are supported by the Crossover LSH-NWO grant INTENSE. F.E.H. is supported by the C.J. Vaillant Fund.

\section{Potential competing interests}

Nothing to report.

\section{Credit author statement - Eelkman Rooda et al}

O.H.J.E.R. performed all experiments with help of L.K, H.J.P. and N.A.J. for recordings and stimulations in head-fixed animals, of S.J.F. and E.A.T. for recordings in freely moving animals, of L.K. for seizure detection and analyses of spike modulation, of P.H. for analysis of ECoG activity, and of S.V.G. for axonal projection analyses; E.A.T., A.M.J.M.v.d.M. and C.I.D.Z. contributed to experimental setups, supervised the project and provided financial support; O.H.J.E.R., L.K. and F.E.H. conceived and designed experiments; O.H.J.E.R., L.K., C.I.D.Z. and F.E.H. wrote the manuscript with help from all coauthors.

\section{Declaration of competing interest}

None.

\section{Acknowledgements}

The authors thank Elize Haasdijk, Erika Sabel-Goedknegt, Mandy Rutteman, Marloes Adank, Jinne Geelen, Beerend Winkelman, Maarten Schenke and Farnaz Nassirinia for excellent technical and analytical support and Thijs Houben, Bas van Hoogstraten, 
Daniël Dumas, Carmen Schäfer, Sander Lindeman, Zhenyu Gao, and Saša Peter for their practical and insightful comments.

\section{Appendix A. Supplementary data}

Supplementary data to this article can be found online at https://doi.org/10.1016/j.brs.2021.05.002.

\section{References}

[1] Fogerson PM, Huguenard JR. Tapping the brakes: cellular and Synaptic Mechanisms that regulate thalamic oscillations. Neuron 2016;92(4):687-704.

[2] Aarabi A, Wallois F, Grebe R. Does spatiotemporal synchronization of EEG change prior to absence seizures? Brain Res 2008;1188:207-21.

[3] Adebimpe A, Aarabi A, Bourel-Ponchel E, Mahmoudzadeh M, Wallois F. Functional brain dysfunction in patients with benign childhood epilepsy as revealed by graph theory. PloS One 2015;10(10).

[4] Beenhakker MP, Huguenard JR. Neurons that fire together also conspire together: is normal sleep circuitry hijacked to generate epilepsy? Neuron 2009;62(5):612-32.

[5] Cressman JR, Ullah G, Ziburkus J, Schiff SJ, Barreto E. The influence of sodium and potassium dynamics on excitability, seizures, and the stability of persistent states: I. Single neuron dynamics. J Comput Neurosci 2009;26(2):159-70.

[6] Danober L, Deransart C, Depaulis A, Vergnes M, Marescaux C. Pathophsyiological mechanisms of genetic absence epilepsy in the rat. Prog Neurobiol 1998;55(1):27-57.

[7] Kobau R, Zahran H, Thurman DJ, Zack MM, Henry TR, Schachter SC, et al. Epilepsy surveillance among adults-19 states, behavioral risk factor surveillance system. Morbidity and mortality weekly report Surveillance summaries 2008 2005:57(6):1-20.

[8] Kwan P, Schachter SC, Brodie MJ. Drug-resistant epilepsy. N Engl J Med 2011;365(10):919-26.

[9] Fisher RS, Velasco AL. Electrical brain stimulation for epilepsy. Nat Rev Neurol 2014:10(5):261-70.

[10] Sprengers M, Vonck K, Carrette E, Marson AG, Boon PAJM. Deep brain and cortical stimulation for epilepsy. Cochrane Database Syst Rev 2017;7.

[11] Fisher RS, Salanova V, Witt T, Worth R, Henry T, Gross R, et al. Electrical stimulation of the anterior nucleus of thalamus for treatment of refractory epilepsy. Epilepsia 2010;51(5):899-908.

[12] Salanova V, Witt T, Worth R, Henry T, Gross R, Nazzaro J, et al. Long-term efficacy and safety of thalamic stimulation for drug-resistant partial epilepsy. Neurology 2015;84(10):1017-25.

[13] Fisher RS, Acevedo C, Arzimanoglou A, Bogacz A, Cross JH, Elger CE, et al. ILAE official report: a practical clinical definition of epilepsy. Epilepsia 2014;55(4): 475-82.

[14] Kros L, Eelkman Rooda OHJ, De Zeeuw CI, Hoebeek FE. Controlling cerebellar output to treat refractory epilepsy. Trends Neurosci 2015;38(12):787-99.

[15] Kros L, Eelkman Rooda OHJ, Spanke JK, Alva P, Van Dongen MN, Karapatis A, et al. Cerebellar output controls generalized spike-and-wave discharge occurrence. Ann Neurol 2015;77(6):1027-49.

[16] Gornati SV, Schafer CB, Eelkman Rooda OHJ, Nigg AL, De Zeeuw CI, Hoebeek FE. Differentiating cerebellar impact on thalamic nuclei. Cell Rep 2018;23(9):2690-704.

[17] Schafer CB, Hoebeek FE. Convergence of primary sensory cortex and cerebellar nuclei pathways in the whisker system. Neuroscience 2018;368: 229-39.

[18] Teune TM, Van der Burg J, Van der Moer J, Ruigrok TJ. Topography of cerebellar nuclear projections to the brain stem in the rat. Prog Brain Res 2000; $124: 141-72$.

[19] Noebels JL, Sidman RL. Spike-Wave and focal motor seizures in the mutant mouse tottering. Science 1979;204(4399):1334-6.

[20] Mattis J, Tye KM, Ferenczi EA, Ramakrishnan C, O'Shea DJ, Prakash R, et al. Principles for applying optogenetic tools derived from direct comparative analysis of microbial opsins. Nat Methods 2012;9(2):159-72.

[21] Gradinaru V, Mogri M, Thompson KR, Henderson JM, Deisseroth K. Optical deconstruction of parkinsonian neural circuitry. Science 2009;324(5925): 354-9.

[22] Houben T, Loonen IC, Baca SM, Schenke M, Meijer JH, Ferrari MD, et al. Optogenetic induction of cortical spreading depression in anesthetized and freely behaving mice. J Cerebr Blood Flow Metabol 2017;37(5):1641-55.

[23] University S. Predicted irradiance values: model based on direct measurements in mammalian brain tissue. http://web.stanford.edu/group/dlab/cgibin/graph/chart.php. [Accessed 16 April 2016].

[24] Van Dongen MN, Hoebeek FE, Koekkoek SKE, De Zeeuw CI, Serdijn W. High frequency switched-mode stimulation can evoke post synaptic responses in cerebellar principal neurons. Front Neuroeng 2015;8(2) [Epub].

[25] Holt GR, Softky WR, Koch C, Douglas RJ. Comparison of discharge variability in vitro and in vivo in cat visual cortex neurons. J Neurophysiol (Bethesda) 1996;75(5):1806-14.

[26] Kundishora AJ, Gummadavelli A, Ma C, Liu M, McCafferty C, Schiff ND, et al. Restoring conscious arousal during focal limbic seizures with deep brain stimulation. Cerebr Cortex 2016;27(3):1964-75.
[27] Kandel A, Buzsáki G. Cerebellar neuronal activity correlates with spike and wave EEG patterns in the rat. Epilepsy Res 1993:16(1):1-9.

[28] Kros L, Lindeman SL, Eelkman Rooda OHJ, De Zeeuw CI, Hoebeek FE. Synchronicity and rhythmicity of Purkinje cell firing during generalized spikeand-wave discharges in a natural mouse model of absence epilepsy. Front Cell Neurosci 2017;11(346).

[29] Bentivoglio M, Kuypers HG. Divergent axon collaterals from rat cerebellar nuclei to diencephalon, mesencephalon, medulla oblongata and cervical cord. A fluorescent double retrograde labeling study. Exp Brain Res 1982;46(3): 339-56.

[30] Kuramoto E, Ohno S, Furuta T, Unzai T, Tanaka YR, Hioki H, et al. Ventral medial nucleus neurons send thalamocortical afferents more widely and more preferentially to layer 1 than neurons of the ventral anterior-ventral lateral nuclear complex in the rat. Cerebr Cortex 2015;25(1):221-35.

[31] Kuramoto E, Furuta T, Nakamura KC, Unzai T, Hioki H, Kaneko T. Two types of thalamocortical projections from the motor thalamic nuclei of the rat: a single neuron-tracing study using viral vectors. Cerebr Cortex 2009;19(9):2065-77.

[32] Van Dongen MN, Karapatis A, Kros L, Eelkman Rooda OHJ, Seepers RM, Strydis C, et al. An implementation of a wavelet-based seizure detection filte suitable for realtime closed-loop epileptic seizure suppression. Lausanne: BioCAS; 2014. p. 504-7.

[33] Chen J, Kriegstein AR. A GABAergic projection from the zona incerta to cortex promotes cortical neuron development. Science 2015;350(6260):554-8.

[34] Valentin A, Garcia Navarrete E, Chelvarajah R, Torres C, Navas M, Vico L, et al Deep brain stimulation of the centromedian thalamic nucleus for the treatment of generalized and frontal epilepsies. Epilepsia 2013;54(10):1823-33.

[35] Proville RD, Spolidoro M, Guyon N, Dugué GP, Selimi F, Isope P, et al. Cerebellum involvement in cortical sensorimotor circuits for the control of voluntary movements. Nat Neurosci 2014;17(9):1233-9.

[36] Sorokin JM, Paz JT, Huguenard JR. Absence seizure susceptibility correlates with pre-ictal B oscillations. J Physiol Paris 2016;110:372-81.

[37] Fletcher CF, Lutz CM, O'Sullivan TN, Shaughnessy JD, Hawkes R, Frankel WN, et al. Absence epilepsy in tottering mutant mice is associated with calcium channel defects. Cell 1996;87(4):607-17.

[38] Zhang Y, Mori M, B DL, Noebels JL. Mutations in high-voltage activated calcium channel genes stimulate low-voltage-activated currents in mouse thalamic relay neurons. J Neurosci 2002;22(15):6362-71.

[39] Song I, Kim D, Choi S, Sun M, Kim Y, Shin HS. Role of the A1G T-type calcium channel in spontaneous absence seizures in mutant mice. J Neurosc 2004;24(22):5249-57.

[40] Sasaki S, Huda K, Inoue T, Miyata M, Imoto K. Impaired feedforward inhibition of the thalamocortical projection in epileptic Ca2 + channel mutant mice, tottering. J Neurosci 2006;26(11):3056-65.

[41] Depaulis A, Charpier S. Pathophysiology of absence epilepsy: insights from genetic models. Neurosci Lett 2017.

[42] Polack PO, Charpier S. Intracellular activity of cortical and thalamic neurones during high-voltage rhythmic spike discharge in Long-Evans rats in vivo. J Physiol 2006;571:461-76.

[43] Polack PO, Mahon S, Chavez M, Charpier S. Inactivation of the somatosensory cortex prevents paroxysmal oscillations in cortical and related thalamic neurons in a genetic model of absence epilepsy. Cerebr Cortex 2009;19(9): 2078-91.

[44] McCafferty C, David F, Venzi M, Lorincz ML, Delicata F, Atherton Z, et al. Cortical drive and thalamic feed-forward inhibition control thalamic output synchrony during absence seizures. Nat Neurosci 2018;21(5):744-56.

[45] Slaght SJ, Leresche N, Deniau JM, Crunelli V, Charpier S. Activity of thalamic reticular neurons during spontaneous genetically determined spike and wave discharges. J Neurosci 2002;22(6):2323-34.

[46] Halassa MM, Acsady L. Thalamic inhibition: diverse sources, diverse scales. Trends Neurosci 2016;39(10):680-93.

[47] Sawyer SF, Young SJ, Groves PM, Tepper JM. Cerebellar-responsive neurons in the thalamic ventroanterior-ventrolateral coplex of rats: in vivo electrophysiology. Neuroscience 1994;63:711-24.

[48] Sorokin JM, Davidson TJ, Frechette E, Abramian AM, Deisseroth K, Huguenard JR, et al. Bidirectional control of generalized epilepsy networks via rapid real-time switching of firing mode. Neuron 2017;93(1):194-210.

[49] Aumann TD, Horne MK. Ramification and termination of single axons in the cerebellothalamic pathway of the rat. J Comp Neurol 1996;376:420-30.

[50] Chevalier G, Deniau JM. Inhibitory nigral influence on cerebellar evoked responses in the rat ventromedial thalamic nucleus. Exp Brain Res 1982;48(3): 369-76.

[51] Cohen D, Chambers WW, Sprague JM. Experimental study of the efferent projections from the cerebellar nuclei to the brainstem of the cat. J Comp Neurol 1958;109(2):233-59.

[52] Popa D, Spolidoro M, Proville RD, Guyon N, Belliveau L, Léna C. Functional role of the cerebellum in gamma-band synchronization of the sensory and motor cortices. J Neurosci 2013;33(15):6552-6.

[53] Sasaki K, Matsuda Y, Mizuno N. Distribution of cerebellar-induced responses in the cerebral cortex. Exp Neurol 1973;39(2):342-54.

[54] Steriade M, Contreras D. Relations between cortical and thalamic cellular events during transition from sleep patterns to paroxysmal activity. J Neurosci 1995; 15(1):623-42.

[55] Uno M, Yoshida M, Hirota I. The mode of cerebello-thalamic relay transmission investigated with intracellular recording from cells of the ventrolateral nucleus of cat's thalamus. Exp Brain Res 1970;10(2):121-39. 
[56] Yoshida M, Yajima K, Uno M. Different activation of the 2 types of the pyramidal tract neurones through the cerebello-thalamocortical pathway. Experientia 1966;22(5):331-2.

[57] Bava A, Cicirata F, Giuffrida R, Licciardello S, Panto MR. Electrophysiologic properties and nature of ventrolateral thalamic nucleus neurons reactive to converging inputs of paleo- and neocerebellar origin. Exp Neurol 1986;91(1): $1-12$.

[58] Bava A, Manzoni T, Urbano A. Effects of fastiginal stimulation on thalamic neurones belonging to the diffuse projection system. Brain Res 1967;4(4): $378-80$.
[59] Witter L, Canto CB, Hoogland TM, de Gruijl JR, De Zeeuw CI. Strength and timing of motor responses mediated by rebound firing in the cerebellar nuclei after Purkinje cell activation. Front Neural Circ 2013;7:133.

[60] Hoogland TM, De Gruijl JR, Witter L, Canto CB, De Zeeuw CI. Role of synchronous activation of cerebellar purkinje cell ensembles in multi-joint movement control. Curr Biol 2015;25(9):1157-65.

[61] Yu C, Derdikman D, Haidarliu S, Ahissar E. Parallel thalamic pathways for whisking and touch signals in the rat. PLoS Biol 2006;4(5):e124. 